\title{
A educomunicação na batalha contra as fake news
}

Maria Cristina Castilho Costa

Professora titular da Escola de Comunicações e Artes (ECA) da Universidade de São Paulo (USP). E-mail: criscast@usp.br

\section{Anderson Vinicius Romanini}

Professor da Escola de Comunicações e Artes (ECA) da Universidade de São Paulo (USP).

E-mail: vinicius.romanini@usp.br

Resumo: Este artigo trabalha com dois conceitos fundamentais, a educomunicação e a desinformação, procurando mostrar que a manipulação de informações e a influência das tecnologias de comunicação sobre a opinião pública têm sido uma preocupação central dos filósofos e estudiosos da comunicação humana. Assim, analisando a desinformação como fenômeno da atualidade, são apresentadas as principais teorias das ciências da comunicação que trazem subsídios para estudá-lo - de perspectivas diferentes, mas complementares. A partir dessa abordagem, questões como democracia, ideologia e poder se tornam elementos aglutinadores dessas análises.

Palavras-chave: desinformação; fake news; big data; educomunicação; teorias da comunicação.
Abstract: This article addresses two fundamental concepts, educommunication and disinformation, trying to show the manipulation of information and that the influence of communication technologies on public opinion has been a central concern of philosophers and scholars of human communication. Thus, analyzing disinformation as a current phenomenon, the main theories of communication sciences are presented, which provide subsidies to study it - from different but complementary perspectives. From this approach, issues such as democracy, ideology and power become elements that bring these analyses together.

Keywords: disinformation; fake news; big data; educommunication; communication theories. 


\section{INTRODUÇÃO}

A difusão de desinformação - conteúdos falsos, imagens adulteradas, notícias descontextualizadas - por meio das redes sociais que operam nas plataformas digitais despertou a atenção global por ter influenciado, se não determinado, os resultados de pleitos democráticos importantes, como o Brexit (plebiscito que decidiu pela saída do Reino Unido da União Europeia); as eleições presidenciais americanas de 2016, que elegeram Donald Trump contra todas as pesquisas de opinião pública da época; e, numa espécie de reação em cadeia, diversas eleições majoritárias que ocorreram contaminadas por fake news, incluindo a de Jair Bolsonaro no Brasil, em $2018^{1}$.

Os pesquisadores das humanidades digitais identificaram tardiamente a dimensão e a importância desse fenômeno. Foram os próprios veículos de comunicação que iniciaram o debate sobre os perigos das fake news para as democracias, ainda em setembro de 2016, com o artigo "Art of the lie" ("Arte da mentira"), publicado pela revista inglesa The Economist, que destacava o termo post-truth (pós-verdade, em português) e culpava a internet e as redes sociais pela disseminação de mentiras por políticos. Meses depois, "pós-verdade" foi eleita como palavra do ano pelo Dicionário Oxford, que a descreve como "circunstâncias nas quais os fatos objetivos são menos influentes na formação da opinião pública do que os apelos à emoção e à crença pessoal”3.

Saturados por fake news que parasitam crenças religiosas fundamentalistas ${ }^{4}$, tais como questões relativas a identidade de gênero, papel da mulher na vida pública, direito ao aborto, expressões da sexualidade etc. (evocadas a partir de imagens e vídeos obscenos, frequentemente grotescos), os participantes da esfera pública digital mais incautos tendem a tomar decisões político-eleitorais contrárias aos seus próprios interesses de classe. Num clima coalhado por indignação mal fundamentada e ódio artificialmente infundido, a opinião pública emerge com um grau de polarização que interdita o debate democrático. Como se vê com frequência cada vez maior, a argumentação perde racionalidade a ponto de se tornar uma guerra de guerrilha sem escrúpulos, na qual leva a melhor quem tem mais granadas digitais e bombas sujas para lançar contra o oponente. Não por acaso, Jeff Giesea ${ }^{5}$ defendeu, na revista oficial da Organização do Tratado do Atlântico Norte (Otan), o uso de memes como estratégia de contrainformação num cenário de conflito global.

As narrativas sobre o hackeamento das democracias ocidentais por grupos da ultradireita ganhavam veracidade à medida que os episódios eram apurados. O caso mais emblemático continua a ser o da eleição presidencial dos Estados Unidos de 2016, que contou com denúncias de roubo de dados e interferência da Rússia com o objetivo de privilegiar a campanha do republicano Donald Trump, que saiu vitorioso na disputa. Em 2017, Google, Facebook e Twitter admitiram $^{6}$ que operadores russos compraram anúncios e exploraram seus serviços para difundir notícias falsas e promover a polarização da sociedade americana. Uma pesquisa realizada pelo jornalista Jonathan Albright e publicada
1. Para ilustrar como se deu a circulação de informações nas eleições de 2018, trazemos alguns dos dados divulgados por agências de checagem de notícias. "De julho a outubro, Aos Fatos desmentiu 113 boatos sobre eleições que, somados, acumularam ao menos 3,84 milhões de compartiIhamentos no Facebook e no Twitter. Apenas no fim de semana do segundo turno, Aos Fatos desmentiu 19 peças de desinformação que, ao todo, foram compartilhadas 290 mil vezes no Facebook" (LIBÓRIO, Bárbara; CUNHA, Ana Rita. Notícias falsas foram compartilhadas ao menos 3,84 milhões de vezes durante as eleições. Aos Fatos, Rio de Janeiro, 31 out. 2018. Disponível em: https://aosfatos. org/noticias/noticias-falsas-foram-compartilhadas-ao-menos-384-milhoes-vezes-durante-eleicoes/. Acesso em: 3 jan. 2020). "Levantamento feito pela Agência Lupa mostrou que as 10 notícias falsas mais populares flagradas entre agosto e outubro tiveram juntas mais de 865 mil compartilhamentos no Facebook" (FAKE news impactam a eleição e têm que ser combatidas. Agência Lupa, Brasília, DF, 22 out. 2018. Disponível em: https://piaui. folha.uol.com.br/lupa/wp-content/uploads/2018/10/ Propostas-checadores-TS. pdf. Acesso em: 3 jan. 2020).

2. ART of the lie. The Economist, London, 10 set. 2016. Disponível em: https:// www.economist.com/leaders/2016/09/10/art-of-the-lie. Acesso em: 12 jul. 2019.

3. WORD of the year 2016. Oxford Languages, Oxford, 8 nov. 2016. Tradução nossa. Disponível em: https://languages.oup.com/ word-of-the-year/2016/. Acesso em: 3 jan. 2020. 
4. BRADY, William J.; WILLS, Julian A.: JOSTA, John T. TUCKER, Joshua A.; VAN BAVEL, Jay J. Emotion shapes the diffusion of moralized content in social networks. Proceedings of the National Academy of Sciences, Washington, DC, v. 114 , n. 28, p. 7313 7318, 2017. Disponível em: https://doi.org/10.1073/ pnas.1618923114. Acesso em: 2 jan. 2020

5. GIESEA, Jeff. It's time to embrace memetic warfare. Defense Strategic Communications, Riga, v. 1 , n. 1, p. 67-76, 2015.

6. ISAAC, Mike; WAKABA YASHI, Daisuke. Russian influence reached 126 million through Facebook alone. The New York Times New York, 30 out. 2017. Disponível em: https://www. nytimes.com/2017/10/30/ technology/facebook-google-russia.html. Acesso em: 31 ago. 2019.

7. TIMBERG, Craig. Russian propaganda may have been shared hundreds of millions of times, new research says. The Washington Post, Washington DC, 5 out. 2017. Disponível em: https://www.washingtonpost.com/news/the-switch/wp/2017/10/05/ russian-propaganda-may-have-been-shared-hundreds-of-millions-of-times-new-research-says/. Acesso em: 3 jan. 2020.

8. ROSENBERG, Matthew; CONFESSORE, Nicholas; CADWALLADR, Carole. How Trump consultants exploited the Facebook data of millions. The New York Times, New York, 17 mar. 2018. Disponível em: https://www.nytimes. com/2018/03/17/us/politics/ cambridge-analytica-trump-campaign.html. Acesso em: 19 ago. 2019 no The Washington Post revelou que as postagens de apenas 6 das cerca de 470 contas russas no Facebook foram compartilhadas mais de 340 milhões de vezes e haviam gerado 19,1 milhões de interações ${ }^{7}$. Os conteúdos incluíam mensagens difamatórias contra a então candidata democrata Hillary Clinton.

Um novo escândalo veio à tona em março de 2018, quando o jornal The New York Times ${ }^{8}$ revelou que a Cambridge Analytica, empresa responsável pela campanha eleitoral de Donald Trump, usou dados roubados de milhões de usuários do Facebook para traçar perfis psicológicos e moldar mensagens personalizadas, capazes de influenciar o comportamento de eleitores. A empresa obteve tais dados por meio de um suposto teste de personalidade, sem revelar que o material seria usado com fins eleitorais, e valeu-se de informações de geolocalização para distribuir mensagens e monitorar sua eficácia em plataformas como Facebook, YouTube e Twitter, conforme reportagem do The Guardian ${ }^{9}$.

Não há mais dúvidas: as redes sociais passaram a ocupar o centro da disputa político-ideológica mundial, relegando para um plano inferior as grandes corporações midiáticas do século XX. Notando que o centro de gravidade das práticas de comunicação social migrava rapidamente para novas milícias digitais, a grande mídia reagiu implantando estratégias para combater as fake news "corpo a corpo", criando rotinas de checagem nas redações ou construindo parcerias com agências especializadas em identificar, avaliar e denunciar notícias falsas. No Brasil, a Agência Lupa ${ }^{10}$ e o projeto Comprova ${ }^{11}$ são os exemplos mais importantes dessas trincheiras que, apesar de louváveis, quase sempre agem na ponta final do problema, quando a maior parte das consequências sociais já foram produzidas. São iniciativas que apenas enxugam o gelo da ponta de um iceberg que se move à deriva por um oceano de desinformação que parece interminável.

\section{O QUE SÃO AS FAKE NEWS?}

O termo fake news será aqui conceituado, de acordo com a definição adotada pela Comissão Europeia (CE), como desinformação intencional "criada, apresentada e divulgada para obter vantagens econômicas ou para enganar deliberadamente o público"12. Essa definição expande a sugerida previamente por Allcott e Gentzkow ${ }^{13}$, que as caracterizavam como "notícias que são intencionalmente e comprovadamente falsas, e podem enganar os leitores". As palavras-chave que as unem são "intencional" e "enganar", o que parece ser um denominador comum entre todas as fake news. No entanto, a CE reconhece que fake news não são necessariamente desinformação empacotada em forma de notícias jornalísticas, mas podem ser qualquer conteúdo enganoso que circule com virulência pelas redes sociais. O encapsulamento do sentido em unidades relativamente pequenas, que podem ser replicadas ad infinitum na lógica das redes sociais, evoca naturalmente o conceito de meme (vídeos, GIFs, fotos ou textos curtos produzidos para as plataformas digitais, na maioria das vezes sem fonte, sem o devido contexto, nem autoria definida). 
Por isso a definição da CE ressalta que o impacto se dá sobre um público muito mais geral do que o de consumidores de notícias produzidas pelos veículos de comunicação, atingindo inclusive os extremos do espectro de faixas etárias (por exemplo, crianças não alfabetizadas e um grande público da terceira idade com baixa escolaridade, que jamais tivera hábito de leitura de notícias). Por fim, a CE também identifica o objetivo econômico associado à difusão das fake news, já que o modelo de negócio de plataformas digitais como Facebook, YouTube, Instagram etc. prioriza a monetização por meio de cliques associados a anúncios produzidos de acordo com os perfis de navegação dos usuários. Nesse formato, por vezes definido como capitalismo digital, o foco da crítica e do estudo de impacto não deve estar apenas nas fake news, mas também na "velocidade $\mathrm{e}$ [...] facilidade de sua disseminação, e isso acontece principalmente porque o capitalismo digital de hoje faz com que seja altamente rentável - veja o Google e o Facebook - produzir e compartilhar narrativas falsas que atraem cliques" ${ }^{14}$.

Pariser ${ }^{15}$ parte do abundante fluxo de dados em circulação na internet $\mathrm{e}$ dos algoritmos usados por diferentes empresas para discorrer sobre a chamada "personalização". Segundo o autor, grandes corporações como Google, Facebook, Apple e Microsoft usam dados pessoais fornecidos por usuários e seus rastros de navegação na rede para personalizar ofertas de informação e, consequentemente, conseguir vender anúncios mais alinhados às preferências de cada usuário. De acordo com Pariser ${ }^{16}$, a personalização altera o modo como as informações circulam na internet. Isso ocorre porque, a partir da avaliação prévia das supostas preferências das pessoas, os algoritmos de sites e redes sociais criam previsões sobre quem elas são e o que gostariam de fazer e, assim, selecionam as informações que cada uma receberá. Esse processo, atualizado e refinado constantemente com base nas interações dos usuários, leva ao que o autor chama de "bolha dos filtros", um mecanismo invisível em que os indivíduos tendem a receber apenas informações alinhadas às suas preferências, aproximando pessoas que têm opiniões semelhantes e afastando as que pensam de forma diferente ${ }^{17}$.

Outro problema é que muitos usuários não têm consciência do funcionamento desse mecanismo. Entre as consequências da personalização e da criação de bolhas estão a limitação da variedade de conteúdos aos quais cada pessoa é exposta, a redução das possibilidades de aprendizado e a restrição na tomada de decisões ${ }^{18}$. Nessa lógica mercantilista sem regulamentação adequada e nenhuma deontologia profissional por parte dos criadores, fake news e conteúdos espetacularizados - desenvolvidos numa estética kitsch que apela ao sentimentalismo piegas ou a emoções patéticas de grande intensidade (paixão visceral ou ódio figadal) - são muito mais lucrativos para seus produtores. $\mathrm{Ou}$ seja, numa espécie de círculo vicioso que opera em movimento contínuo, fake news já viralizadas e convertidas em dinheiro financiam a próxima rodada de fake news ainda por viralizar.

Esse modelo econômico típico das plataformas digitais e a disponibilidade cada vez maior de dados utilizados indevidamente por empresas de marketing
9. LEWIS, Paul; HILDER Paul. Leaked: Cambridge Analytica's blueprint for Trump victory. The Guardian, London, 23 mar. 2018. Disponível em: https:// www.theguardian.com/ uk-news/2018/mar/23/ leaked-cambridge-analyticas-blueprint-for-trump-victory. Acesso em: 31 ago. 2019.

10. Site da Agência Lupa: https://piaui.folha.uol.com br/lupa/.

11. Site do projeto Comprova: https://projetocomprova.com.br/.

12. COMISSÃO EUROPEIA. Comunicação da Comissão ao Parlamento Europeu, ao Conselho, ao Comitê Econômico e Social Europeu e ao Comitê das Regiões: combater a desinformação em linha: uma estratégia europeia. Bruxelas: Comissão Europeia, 2018. Disponível em: https://eur-lex.europa.eu/legal-content/PT/TXT/PDF/?uri=CELEX:52018DC0236\&qid $=1525280608825 \&$ from $=E N$. Acesso em: 16 mar. 2019. p. 4.

13. ALLCOTT, Hunt; GENTZKOW, Matthew. Social media and fake news in the 2016 election. Journal of Economic Perspectives, Nashville, v. 31, n. 2, p. 211-236, 2017. p. 213, tradução nossa. Disponível em: https://doi.org/10.1257/ jep.31.2.211. Acesso em: 2 jan. 2020.

14. MOROZOV, Evgeny. Big tech: a ascensão dos dados e a morte da política. São Paulo: Ubu, 2018. p. 185.

15. PARISER, Eli. The filter bubble: what the internet is hiding from you. New York: The Penguin Press, 2011.

16. Ibidem.

17. Ibidem, p. 14.

18. Ibidem, p. 77. 
19. CHESNEY, Robert CITRON, Danielle Keats. Deep fakes: a looming challenge for privacy, democracy, and national security. SSRN Electronic Journal, Amsterdam, 21 jul. 2018. Disponível em: https://dx.doi.org/10.2139/ ssrn.3213954. Acesso em: 3 jan. 2020.

20. KITCHIN, Rob. Big data, new epistemologies and paradigm shifts. Big Data \& Society, Thousand Oaks, p. 1-12, 1 abr. 2014 Disponível em: https://doi. org/10.1177/20539517145 28481. Acesso em: 3 jan. 2020

21. Ibidem, p. 1.

22. Ibidem, p. 2.

23. BOYD, danah; CRAWFORD, Kate. Critical questions for big data: provocations for a cultural, technological, and scholarly phenomenon. Information, Communication \& Society, Abing don, v. 15 , n. 5, p. 662-679, 2012. Disponível em: https://people.cs.kuleuven. be/ bettina.berendt/ teaching/ViennaDH15/ boyd_crawford_2012.pdf. Acesso em: 24 out. 2019. e partidos criaram um modus operandi de produção de conteúdo político para campanhas eleitorais que viola padrões éticos, legislações e direitos humanos para atingir seus objetivos. O problema deve se agravar ainda mais com a chegada das deep fake news, que usam algoritmos inteligentes, baseados no aprendizado de máquina, para criar vídeos em que a imagem e a voz de qualquer pessoa podem ser introduzidas em situações constrangedoras ou criminosas, sem que o grande público tenha competência para discernir entre o que é realidade e o que é falsidade criada computacionalmente para atingir propósitos espúrios, quase sempre de controle e domínio da esfera pública digital ${ }^{19}$.

\section{A ERA DO BIG DATA E OS PERIGOS DO DATAÍSMO}

A coleta de grandes volumes de dados não é um fenômeno novo. Pesquisas censitárias, cadastros de empresas e transações bancárias, por exemplo, já envolviam a criação de enormes bancos de dados. Entretanto, com o avanço da computação ubíqua e da internet, o aumento exponencial na quantidade de dados produzidos, armazenados e compartilhados por e sobre pessoas e suas interações tem sido alvo de diversas discussões sobre as potencialidades e consequências de seu uso. Mas o que diferencia o fenômeno contemporâneo conhecido como big data de outras formas de coleta de dados?

Em artigo que discute as implicações epistemológicas do big data, Kitchin ${ }^{20}$ argumenta que o termo não pode ser compreendido apenas em relação ao volume de dados. Segundo o autor, outras características do big data são: a produção contínua e em grande velocidade; a variedade dos dados; a exaustividade e o refinamento no escopo; a natureza relacional dos dados, com possibilidade de junção entre diferentes tipos; a flexibilidade e a escalabilidade ${ }^{21}$. Mais do que o tipo, a quantidade ou a velocidade com que os dados são produzidos, o big data está relacionado a uma nova maneira de armazenar, analisar e correlacionar dados a partir das possibilidades trazidas pelo desenvolvimento de computadores de alta potência, de novas técnicas de análise e de tecnologias como a inteligência artificial, que permitem a detecção de padrões e a construção de modelos preditivos ${ }^{22}$.

danah boyd e Kate Crawford ${ }^{23}$ compreendem o big data como um fenômeno cultural, tecnológico e acadêmico, baseado na interação entre as tecnologias, os tipos de análise e a falsa crença de que grandes quantidades de dados são suficientes para gerar uma nova forma de conhecimento objetivo, preciso e verdadeiro. Diante da ascensão do big data, as autoras alertam sobre a necessidade de uma reflexão crítica sobre o tema e propõem questionamentos sobre a origem dos dados, as formas de acesso, os diversos interesses envolvidos, as suposições e os vieses relacionados aos dados.

Hoje a coleta de dados ocorre por meio de diferentes atividades, tais como o uso de smartphones, cliques em sites, transações bancárias, compartilhamento de informações pessoais em redes sociais digitais, uso de GPS, cadastramento 
em sistemas de controle governamentais, registro de impressão digital, uso de objetos legíveis por máquinas, como passes de viagem ou códigos de barras, compras e navegação on-line, entre outras ${ }^{24}$. Just e Latzer ${ }^{25}$ explicam que esse aumento do fluxo de dados digitais gerou o crescimento da demanda por seleção algorítmica automatizada com o objetivo de lidar com a quantidade massiva de dados coletados. Os autores esclarecem, assim, que o big data e o processo de seleção algorítmica estão interligados, pois o primeiro funciona como "uma nova classe de ativos econômicos", enquanto o segundo representa "um novo método para extrair valor social e econômico dos dados" 26 .

Por big data, no entanto, não entendemos apenas a nova era digital dos bancos de dados que coletam, em tempo real e a partir de dispositivos móveis computadorizados, quantidades imensas de informações, que chegam continuamente e com imensa diversidade de fontes e parâmetros. Essa é uma definição mais próxima da materialidade do fenômeno. O que desejamos enfatizar, na era do big data, é a nascente epistemologia que a acompanha, o chamado dataísmo ${ }^{27}$, fundamentado sobre a crença em um novo conjunto de instrumentos metodológicos de busca e rastreamento de correlações entre os dados digitais acumulados, de forma a criar hipóteses preditivas impossíveis de serem alcançadas por outros métodos.

De fato, Pearl e Mackenzie ${ }^{28}$ mostram que os métodos e as técnicas de big data permitem aos cientistas sociais encontrar nos bancos de dados correlações "invisíveis" aos métodos tradicionais de pesquisa científica, ampliando a confiabilidade das hipóteses. O dataísmo, como epistemologia emergente, contrapõe-se e mesmo desdenha dos métodos estatísticos feitos a partir de amostragem e com margens de erro e confiança atrelados à quantidade de casos observados no interior de um domínio ou universo especificado - caso das pesquisas de opinião pública tradicionais. Como admite que o domínio da pesquisa é o próprio universo de interesse, ou seja, que a extração continuada de informações dos indivíduos esgota as possibilidades de conhecimento, além de representar com fidelidade e em tempo real as flutuações de intensidade dos parâmetros escolhidos para a observação, o dataísmo ${ }^{29}$ assume "proxies" digitais como representantes perfeitos do estado dos sistemas sociais complexos em determinados intervalos de tempo.

No dataísmo, sondar correlações, estimular ou restringir ações sobre proxies digitais têm o mesmo valor cognitivo que a pesquisa sobre a realidade dos fenômenos. Mais concretamente, um algoritmo que, a partir de certas regras inscritas num programa, aplica uma pena punitiva ao perfil virtual de um usuário de redes sociais corresponde perfeitamente a um juiz que aplica punição ao cidadão imputável pelas leis que o alcançam. Na verdade, a ação do algoritmo sobre os dados passa a embasar, se não determinar, a decisão do juiz. Esse determinismo é um resquício da epistemologia científica iluminista que avanços posteriores advindos da termodinâmica e da própria teoria matemática da informação pareciam ter eliminado da cultura científica ocidental. No entanto o dataísmo, metafisicamente, recupera o sonho de uma determinação completa
24. KITCHIN, op. cit., p. 4.

25. JUST, Natascha; LATZER, Michael. Governance by algorithms: reality construction by algorithmic selection on the internet. Media, Culture \& Society, Thousand Oaks, v. 39, n. 2, p. 238 258, 2016. Disponível em https://doi.org/10.1177/ 0163443716643157. Acesso em: 3 jan. 2020.

26. Ibidem, p. 240, tradução nossa.

27. VAN DIJCK, José. Datafication, dataism and dataveillance: big data between scientific paradigm and ideology. Surveillance \& Society, Chapel Hill, v. 12, n. 2, p. 197-208, 2014. Disponível em: https://doi. org/10.24908/ss.v12i2.4776. Acesso em: 3 jan. 2020.

28. PEARL, Judea; MACKENZIE, Dana. The book of why. New York: Basic Books, 2018.

29. LOHR, Steve. Data-ism: the revolution transforming decision making, consumer behavior, and almost everything else. New York: Harper Business, 2015. 
e inequívoca dos fenômenos, em que as relações de causa e efeito não estejam obnubiladas sob a névoa da imprevisibilidade estatística. Em poucas palavras: no dataísmo, correlações são naturalmente aceitas como causações.

Sob a epistemologia do dataísmo, em um contexto onde os objetos do mundo, dispostos nas mais diversas áreas das ciências - tais como as da computação, a física, a matemática, a ciência política, a bioinformática, a sociologia etc. -, vêm sendo afetados pelo crescente uso do big data ${ }^{30}$, as opiniões dos indivíduos, por consequência, não escapam ao irrefreável movimento de datificação.

\section{O PAPEL DA EDUCOMUNICAÇÃO}

A complexidade do fenômeno das fake news exige, portanto, medidas igualmente complexas, com abordagens transversais e multidisciplinares. Por ser um efeito colateral da cibercomunicação e depender, para a eficácia de suas estratégias, de um conjunto de conhecimentos e valores compartilhados por uma variedade imensa de comunidades que dividem o mesmo campo de experiências no ciberespaço, a educomunicação surge naturalmente como uma estratégia de intervenção. Como campo teórico-prático emergente na interface entre educação e comunicação, com linhas de atuação que desenvolvem a apropriação crítica do conteúdo midiático, de forma participativa e criativa, a educomunicação tem um importante papel reservado (embora ainda timidamente ocupado) na busca de soluções para o problema das fake news.

A preocupação com a desinformação e com o poder manipulador de mensagens cuja origem, intenção, procedência e significado são desconhecidos é muito antiga - tem registro no século VI a.C., com o mito da caverna de Platão. Sabido por todos, ao menos por aqueles que se inserem no campo das ciências da comunicação, trata-se de uma alegoria, publicada no livro A República, de Platão ${ }^{31}$, que propõe o seguinte dilema: um grupo de homens acorrentados em uma caverna, diante de uma parede que reflete imagens projetadas a partir do exterior, vivem amedrontados imaginando serem reflexos de seres perigosos que os aguardam do lado de fora. Conseguindo se livrar dessa prisão, um dos homens ascende ao exterior e descobre a manipulação das projeções, mas tenta inutilmente alertar os demais, que continuam imobilizados pelas imagens aterrorizantes.

Também chamado de "alegoria da caverna", esse mito busca alertar os atenienses antigos para os equívocos a que estão sujeitos aqueles que não querem sair do conforto de seus preconceitos e rever suas interpretações de mundo. Embora a cultura helênica estivesse muito distante da sociedade da informação, os gregos já compreendiam as consequências desse tipo de mistificação numa

30. BOYD; CRAWFORD, op. cit., p. 663.

31. PLATÃO. A República. Rio de Janeiro: Best Seller: 2002 sociedade que descobrira a vida pública e participativa e a capacidade humana de pensar a realidade por meio de argumentos, muito além da visão revelacionista dos demais povos antigos. Portanto a importância desse mito está em suas consequências para a democracia e a vida pública e participativa. Essa herança helênica tem sido inestimável - à medida que a sociedade se complexifica, 
no Ocidente, mais nos preocupamos em saber o que constitui efetivamente a realidade e em defender uma comunicação pública, livre e não manipuladora.

$\mathrm{Na}$ modernidade, retomando-se a herança clássica e organizando-se uma sociedade urbana, diversificada e, até certo ponto, anônima, as bases em que a comunicação é produzida e processada se tornam cada vez mais importantes. O desenvolvimento da educação e da ciência permitiu a organização de um pensamento voltado para a defesa da liberdade e da desconstrução das formas possíveis de manipulação de ideias e valores. Juntamente com o desenvolvimento dos meios de comunicação, progressivamente mais sofisticados, cresce o interesse por desvendar os meandros das mensagens que desinformam. Esse interesse se torna mais profundo à medida que a sociedade moderna se democratiza, de modo que regimes centralizadores e autoritários cedem para formas mais ecléticas, participativas e constitucionais, que valorizam a individualidade, a postura crítica e a participação - uma sociedade que se organiza em torno de uma vida pública diversa, intensa e dinâmica.

Podemos identificar pelo menos três grandes grupos de pensadores que desenvolvem teorias da comunicação procurando investigar essa ingenuidade ou dificuldade de percebermos as formas de manipulação que se desenvolvem na imprensa e nos demais meios de comunicação. O primeiro deles é composto por autores como Walter Lippmann ${ }^{32}$, que explora o fato de que as informações que circulam na sociedade são de segunda mão e geram, por sua assiduidade e seus estereótipos, uma opinião pública altamente sugestionada e direcionada pelas grandes agências mediáticas. Essa preocupação com aquilo que constitui, de forma geral, a visão de uma sociedade sobre a realidade vai ser a base de autores que analisam a comunicação como forma de poder em disputa com outras instituições, como a legislativa e a executiva.

Um outro grupo de pesquisadores também aborda as questões de poder, mas trabalhando com o conceito central de ideologia, que podemos definir como um conjunto de ideias que orientam nossa percepção de realidade, impedindo-nos de discernir desvios e equívocos sobre os valores e a compreensão crítica da vida da sociedade. Embora já utilizado por Francis Bacon, antes de Karl Marx, como explicação para as ilusões de realidade produzidas pela cultura de um grupo, pelo teatro e pelo mercado, é na teoria marxista que o conceito adquire substância e força política. Tratado principalmente em $A$ ideologia alema $\tilde{a}^{33} \mathrm{e}$ $O$ capital $^{34}$, o conceito de ideologia aponta a correspondência entre a inserção dos agentes em uma dada estrutura produtiva, os interesses que daí decorrem e a visão de mundo que corrobora a defesa desses interesses. Dessa forma, a ideologia se expressa nas ideias que são proferidas e defendidas e na forma como, em um conflito ideológico permanente, elas lutam por hegemonia. O uso dos meios de comunicação encobre essas tendências e o poder manipulador da mídia.

Nessa linha de investigação, inúmeros autores marxistas se notabilizaram, especialmente os da chamada Escola de Frankfurt, como Theodor Adorno e Walter Benjamin $^{35}$, que exploraram as possibilidades de governos autoritários estabelecerem alianças com as grandes empresas de comunicação, aliciando as massas a seu
32. LIPPMANN, Walter. Opinião pública. Petrópolis: Vozes, 2008

33. MARX, Karl. A ideologia alemã. São Paulo: Martins Fontes, 2002.

34. MARX, Karl. O capital: crítica da economia política: livro 1: o processo de produção capitalista. 2. ed. Rio de Janeiro: Civilização Brasileira, 1971.v. 1 .

35. BENJAMIN, Walter. Escritos sobre mito e linguagem. São Paulo: Duas Cidades: Editora 34, 2011. 
36. BOURDIEU, Pierre. A economia das trocas linguísticas: o que falar quer dizer. São Paulo: Edusp, 1996

37. BAUDRILLARD, Jean. Simulacros e simulação. Lisboa: Antropos, 1991.

38. DEBORD, Guy. A sociedade do espetáculo. Lisboa: Edições Afrodite, 1972.

39. BAKHTIN, Mikhail. Marxismo e filosofia da linguagem: problemas fundamentais do método sociológico na ciência da linguagem. 7. ed. São Paulo: Hucitec, 1993.

40. SEARLE, John. Expressão e significado. São Paulo: Martins Fontes, 1955. ideário político. Acrescida do poder dos meios de comunicação massificadores, a ideologia se torna cada vez menos perceptível em seu poder de estimular condutas e disseminar valores, embotando o espírito crítico e trabalhando com desejos substitutivos da participação política e da luta pela defesa dos próprios interesses. Disfarçada na propaganda, no consumismo e nas formas modernas e contemporâneas de entretenimento, a ideologia se torna um trunfo imbatível na luta pelo poder. Também se encontram outros importantes pesquisadores trabalhando com o poder simbólico, como Pierre Bourdieu ${ }^{36}$, além de Jean Baudrillard ${ }^{37}$ e Guy Debord $^{38}$, este último com uma obra seminal - A sociedade do espetáculo - em que analisa a cultura ocidental em sua perversa relação com o capitalismo.

Uma terceira via nas ciências da comunicação é encontrada no campo do estudo da linguagem. Autores como Ludwig Wittgenstein, Mikhail Bakhtin ${ }^{39}$, John Austin e John Searle ${ }^{40}$ debruçam-se sobre métodos que, investigando as funções simbólicas da fala, desconstroem as mensagens em suas instâncias inconscientes, como o uso de palavras cujo significado, embora histórico, tem origens por vezes desconhecidas. Com essa metodologia, expõem também as trocas simbólicas que se estabelecem na comunicação, orientando o que é dito, ouvido, observado e visto, e conduzindo nossa interação comunicativa com o outro.

É a partir desses grupos de teorias, embora existam outros, assim como pesquisas que tentam costurar uma teoria à outra, que se desenvolveu a educomunicação, um campo interdisciplinar que prevê, como antídoto para essas diferentes e complexas formas de manipulação da cultura, da comunicação e dos meios, uma intervenção social cujo objetivo é libertar aqueles que estão presos na caverna de Platão. Além disso, a educomunicação é um campo vasto e complexo que busca, por um lado, alfabetizar o público em relação aos meios de comunicação, explorando suas possibilidades discursivas e a forma como a tecnologia enforma e informa produtos e mensagens, permitindo diferentes interpretações do mundo que nos cerca. Por outro lado, consciente da desigual distribuição de acesso aos meios de comunicação e produção de informações, a educomunicação busca instruir o público sobre formas alternativas de comunicação, favorecendo a criação e o uso de canais populares de veiculação de mensagens, com autonomia e até em oposição à chamada grande mídia. Espera-se, assim, dar voz a quem não encontra espaço de fala e trabalhar pela diversidade de expressões de ideias.

Também é preocupação da educomunicação a defesa da liberdade de expressão e dos direitos individuais, com livre manifestação em todos os meios disponíveis. Como vimos, a batalha simbólica pelos meios de comunicação, pela hegemonia ideológica e pelo uso da comunicação como forma de acessar e manter o poder induz a inúmeros mecanismos que tentam limitar a crítica, a denúncia, o diálogo e a oposição. Trabalhar pela liberdade de expressão é, portanto, tarefa do educomunicador. Batalhar pelo fortalecimento da democracia é lutar pela democratização da comunicação. É fazer com que as teorias da comunicação sejam a base para uma cultura cada vez mais dialógica, diversificada e libertadora.

Na América Latina e no Brasil, diversos pesquisadores da comunicação se dedicaram ao desenvolvimento da educomunicação. Alguns dos nomes mais 
conhecidos são os de Jesús Martín-Barbero ${ }^{41}$, pesquisador espanhol que vive na Colômbia, Guillermo Orozco Gómez, no México, e Néstor García Canclini, sociólogo argentino que vive no México. No Brasil, desde Mário de Andrade, as preocupações dos educadores se voltam para a produção cultural e simbólica. Paulo Freire teve reconhecimento internacional e continua sendo patrono dos educomunicadores. Aqui, a educomunicação é estudada nas universidades e já se tornou uma formação acadêmica - pelas mãos de professores como Ismar de Oliveira Soares, Maria Aparecida Baccega e Adilson Odair Citelli. Este artigo, para reviver essa contribuição, parte de um fenômeno atual como as fake news para entender toda sua urgência e atualidade.

\section{REFERÊNCIAS BIBLIOGRÁFICAS}

ALLCOTT, Hunt; GENTZKOW, Matthew. Social media and fake news in the 2016 election. Journal of Economic Perspectives, Nashville, v. 31, n. 2, p. 211236, 2017. Disponível em: https://doi.org/10.1257/jep.31.2.211. Acesso em: 2 jan. 2020.

ART of the lie. The Economist, London, 10 set. 2016. Disponível em: https:// www.economist.com/leaders/2016/09/10/art-of-the-lie. Acesso em: 12 jul. 2019.

BAKHTIN, Mikhail. Marxismo e filosofia da linguagem: problemas fundamentais do método sociológico na ciência da linguagem. 7. ed. São Paulo: Hucitec, 1993.

BAUDRILLARD, Jean. Simulacros e simulação. Lisboa: Antropos, 1991.

BENJAMIN, Walter. Escritos sobre mito e linguagem. São Paulo: Duas Cidades: Editora 34, 2011.

BOURDIEU, Pierre. A economia das trocas linguísticas: o que falar quer dizer. São Paulo: Edusp, 1996.

BOYD, danah; CRAWFORD, Kate. Critical questions for big data: provocations for a cultural, technological, and scholarly phenomenon. Information, Communication \& Society, Abingdon, v. 15, n. 5, p. 662-679, 2012. Disponível em: https://people.cs.kuleuven.be/ bettina.berendt/teaching/ViennaDH15/ boyd_crawford_2012.pdf. Acesso em: 24 out. 2019.

BRADY, William J.; WILLS, Julian A.; JOSTA, John T.; TUCKER, Joshua A.; VAN BAVEL, Jay J. Emotion shapes the diffusion of moralized content in social networks. Proceedings of the National Academy of Sciences, Washington, DC, v. 114, n. 28, p. 7313-7318, 2017. Disponível em: https://doi.org/10.1073/ pnas.1618923114. Acesso em: 2 jan. 2020.

CHESNEY, Robert; CITRON, Danielle Keats. Deep fakes: a looming challenge for privacy, democracy, and national security. SSRN Electronic Journal, Amsterdam,

41. MARTÍN-BARBERO, Jesús. A comunicação na educação. São Paulo: Contexto, 2014. 
21 jul. 2018. Disponível em: https://dx.doi.org/10.2139/ssrn.3213954. Acesso em: 3 jan. 2020.

COMISSÃO EUROPEIA. Comunicação da Comissão ao Parlamento Europeu, ao Conselho, ao Comitê Econômico e Social Europeu e ao Comitê das Regiões: combater a desinformação em linha: uma estratégia europeia. Bruxelas: Comissão Europeia, 2018. Disponível em: https://eur-lex.europa.eu/legal-content/PT/ TXT/PDF/?uri=CELEX:52018DC0236\&qid=1525280608825\&from=EN. Acesso em: 16 mar. 2019.

DEBORD, Guy. A sociedade do espetáculo. Lisboa: Edições Afrodite, 1972.

FAKE news impactam a eleição e têm que ser combatidas. Agência Lupa, Brasília, DF, 22 out. 2018. Disponível em: https://piaui.folha.uol.com.br/ lupa/wp-content/uploads/2018/10/Propostas-checadores-TS.pdf. Acesso em: 3 jan. 2020.

GIESEA, Jeff. It's time to embrace memetic warfare. Defense Strategic Communications, Riga, v. 1, n. 1, p. 67-76, 2015.

ISAAC, Mike; WAKABAYASHI, Daisuke. Russian influence reached 126 million through Facebook alone. The New York Times, New York, 30 out. 2017. Disponível em: https://www.nytimes.com/2017/10/30/technology/facebookgoogle-russia.html. Acesso em: 31 ago. 2019.

JUST, Natascha; LATZER, Michael. Governance by algorithms: reality construction by algorithmic selection on the internet. Media, Culture \& Society, Thousand Oaks, v. 39, n. 2, p. 238-258, 2016. Disponível em: https://doi. org/10.1177/0163443716643157. Acesso em: 3 jan. 2020.

KITCHIN, Rob. Big data, new epistemologies and paradigm shifts. Big Data \& Society, Thousand Oaks, p. 1-12, 1 abr. 2014. Disponível em: https://doi. org/10.1177/2053951714528481. Acesso em: 3 jan. 2020.

LEWIS, Paul; HILDER, Paul. Leaked: Cambridge Analytica's blueprint for Trump victory. The Guardian, London, 23 mar. 2018. Disponível em: https:/ / www.theguardian.com/uk-news/2018/mar/23/leaked-cambridge-analyticasblueprint-for-trump-victory. Acesso em: 31 ago. 2019.

LIBÓRIO, Bárbara; CUNHA, Ana Rita. Notícias falsas foram compartilhadas ao menos 3,84 milhões de vezes durante as eleições. Aos Fatos, Rio de Janeiro, 31 out. 2018. Disponível em: https://aosfatos.org/noticias/noticias-falsas-foramcompartilhadas-ao-menos-384-milhoes-vezes-durante-eleicoes/. Acesso em: 3 jan. 2020.

LIPPMANN, Walter. Opinião pública. Petrópolis: Vozes, 2008.

LOHR, Steve. Data-ism: the revolution transforming decision making, consumer behavior, and almost everything else. New York: Harper Business, 2015. 
MARTÍN-BARBERO, Jesús. A comunicação na educação. São Paulo: Contexto, 2014.

MARX, Karl. O capital: crítica da economia política: livro 1: o processo de produção capitalista. 2. ed. Rio de Janeiro: Civilização Brasileira, 1971. v. 1.

MARX, Karl. A ideologia alemã. São Paulo: Martins Fontes, 2002.

MOROZOV, Evgeny. Big tech: a ascensão dos dados e a morte da política. São Paulo: Ubu, 2018.

PARISER, Eli. The filter bubble: what the internet is hiding from you. New York: The Penguin Press, 2011.

PEARL, Judea; MACKENZIE, Dana. The book of why. New York: Basic Books, 2018.

PLATÃO. A República. Rio de Janeiro: Best Seller: 2002.

ROSENBERG, Matthew; CONFESSORE, Nicholas; CADWALLADR, Carole. How Trump consultants exploited the Facebook data of millions. The New York Times, New York, 17 mar. 2018. Disponível em: https:/ / www.nytimes.com/2018/03/17/ us/politics/cambridge-analytica-trump-campaign.html. Acesso em: 19 ago. 2019.

SEARLE, John. Expressão e significado. São Paulo: Martins Fontes, 1955.

TIMBERG, Craig. Russian propaganda may have been shared hundreds of millions of times, new research says. The Washington Post, Washington, DC, 5 out. 2017. Disponível em: https://www.washingtonpost.com/news/the-switch/ wp/2017/10/05/russian-propaganda-may-have-been-shared-hundreds-ofmillions-of-times-new-research-says/. Acesso em: 3 jan. 2020.

VAN DIJCK, José. Datafication, dataism and dataveillance: big data between scientific paradigm and ideology. Surveillance \& Society, Chapel Hill, v. 12, n. 2, p. 197-208, 2014. Disponível em: https://doi.org/10.24908/ss.v12i2.4776. Acesso em: 3 jan. 2020.

WORD of the year 2016. Oxford Languages, Oxford, 8 nov. 2016. Disponível em: https:/ /languages.oup.com/word-of-the-year/2016/. Acesso em: 3 jan. 2020. 